\title{
TITLE:
}

\section{Calling activity of an anuran assemblage in a temporary pond in a dry forest of Madagascar}

$\operatorname{AUTHOR}(S)$ :

Mori, Akira; Ikeuchi, Isami; Hasegawa, Masami

\section{CITATION:}

Mori, Akira ...[et al]. Calling activity of an anuran assemblage in a temporary pond in a dry forest of Madagascar. Current Herpetology 2015, 34(2): 140-148

ISSUE DATE:

2015-08-01

URL:

http://hdl.handle.net/2433/230202

\section{RIGHT:}

(c) 2015 by The Herpetological Society of Japan.; The full-text file will be made open to the public on 01 Aug 2017 in accordance with publisher's 'Terms and Conditions for Self-Archiving'. 


\title{
Calling Activity of an Anuran Assemblage in a Temporary Pond in a Dry Forest of Madagascar
}

\author{
AKIRA MORI $^{1 *}$, IsAmi IKEUCHI ${ }^{1,2}$, AND MASAMI HASEGAWA $^{3}$ \\ ${ }^{1}$ Department of Zoology, Graduate School of Science, Kyoto University, Sakyo, Kyoto \\ 606-8502, JAPAN \\ ${ }^{2}$ Present address: Muko, Kyoto 617-0001, JAPAN \\ ${ }^{3}$ Department of Biology, Faculty of Science, Toho University, Funabashi, Chiba 274-8510, \\ JAPAN
}

\begin{abstract}
Temporary pools are important resources for animals that have aquatic stages during their life history, and particularly for those living in dry climate regions. We investigated the breeding activity of an anuran assemblage in a small temporary pond in the Ampijoroa dry forest of Ankarafantsika National Park, northwestern Madagascar, during the first half of the rainy season from 2000 to 2001 and during the entire rainy season and the beginning of the dry season from 2003 to 2004 . We also surveyed the anuran fauna of Ampijoroa throughout the long-term research conducted from 1999 to 2014. We estimated the breeding activity based on the calling intensity of male frogs. A total of 12 species of frogs was recorded, and eight out of them were confirmed to breed in the temporary pond. These eight species consisted of five families, including one introduced species. The initiation of calling activity seemed to be affected by rainfall in several species. Five of the eight species (Ptychadena mascareniensis, Boophis doulioti, Blommersia wittei, Heterixalus luteostriatus and $\boldsymbol{H}$. tricolor) were considered prolonged breeders, and the other three (Laliostoma labrosum, Hoplobatrachus tigerinus, and Dyscophus insularis) were considered explosive breeders. Two species (Mantidactylus ulcerosus and Stumpffia sp.) were not observed to use the temporary pond for their breeding sites. Neither calls nor breeding sites of the remaining two species (Scaphiophryne calcarata and Mantella ebenaui) were confirmed, although they have been described to breed in stagnant water. This study indicates that temporary ponds in the Ampijoroa forest, which are quite limited in number, provide important habitat for reproduction of frogs, which are living in a harsh environment.
\end{abstract}

Key words: Temporary pond; Dry forest; Madagascar; Frog; Calling activity; Explosive breeder; Prolonged breeder

\section{INTRODUCTION}

Temporary pools, the habitat that intermittently has standing water, is an important

* Corresponding author. E-mail address: gappa@ ethol.zool.kyoto-u.ac.jp study subject for ecology (Blaustein and Schwartz, 2001). This habitat, once inundated, holds water long enough for some species to complete aquatic phases of their life cycles. One representative animal group that often depends on temporary pools is the Anura, and many ecological studies have been con- 
ducted on anuran communities in temporary ponds (e.g., Eason and Fauth, 2001; Abrunhosa et al., 2006; Moreira et al., 2007). Temporary ponds would be especially important as breeding sites in a dry habitat, where availability of standing water is limited both spatially and temporally.

Frogs in Madagascar, like other vertebrate taxa, show extensive speciation and ecological diversity with adaptive radiations (Goodman and Benstead, 2005; Vieites et al., 2009). Most of the frogs of Madagascar are distributed in rainforests, but several species adapted to dry habitats are also present (Glaw and Vences, 2003, 2007). In dry climate regions, where distinct dry and rainy seasons exist, frogs usually breed in ephemeral water bodies available only during the rainy season and remain inactive during the dry season (Glaw and Vences, 2003). Because availability of suitable water bodies for oviposition is temporally and spatially limited, most species of frogs in such a dry habitat may aggregate in a certain area for breeding.

In the present study, we studied breeding activity patterns of frogs in a temporary pond located in a dry forest of Ampijoroa, Ankarafantsika National Park, northwestern Madagascar to investigate the anuran assemblage and its dependency on the temporary pond in a dry habitat. By evaluating the intensity of calling by male frogs, we estimated the activity level of the frogs during the rainy season and evaluated the importance of the temporary pond as breeding sites of the anuran assemblage. We also report on the anuran fauna of this forest based on a 15 year long-term research project and present basic morphometrics on the species.

\section{Materials ANd Methods}

An intensive field study was conducted in Ampijoroa, Ankarafantsika National Park located in the northwestern region of Madagascar $\left(16^{\circ} 19^{\prime} \mathrm{S}, 46^{\circ} 49^{\prime} \mathrm{E}\right)$ from 21 October 2000 to 18 January 2001 and from 22 October 2003 to 26 June 2004. The dry season usually lasts from
May to October, and the rainy season starts gradually in November (see Fig. 1 in Ikeuchi et al., 2012). The annual precipitation in the region is between 1000 and $1500 \mathrm{~mm}$. The forest is split by a road, Route Nationale (RN) 4 , into eastern and western parts, and it includes one botanical garden each on the southwestern and northeastern sides. Between the gardens, Lake Ravelobe (area ca. 30 ha; see Fig. 4 in Mori et al., 2006) is situated along the eastern side of RN 4. The forest station at Ampijoroa, where office facilities, campsites for researchers and ecotourists, the Chelonian Captive Breeding Centre, and several resident houses are located, is situated on the western side of RN 4 and is approximately $1 \mathrm{~km}$ east of the southwestern botanical garden. Paddy fields, which are inundated only during the rainy season, are spread along the southeastern side of RN 4. The vegetation consisted of a deciduous canopy $10-15 \mathrm{~m}$ high and a fairly sparse understory. Approximately $100 \mathrm{~m}$ northwest of the station, there is a small open area (ca $80 \times 60 \mathrm{~m}$; see Fig. 5 in Mori et al., 2006) surrounded by deciduous trees, which is inundated only during the rainy season, creating a temporary pond. The center of the open area is muddy and the remaining area has low, grassy vegetation. In the dry season, few or no water bodies are left in this area, but in the rainy season almost the entire area may be submerged.

In the first season (2000-2001) we made intensive censuses and measured several environmental variables (see below). We censused the open area by slowly walking around the pond and the grassy area every night from 21 October to 18 December 2000 and every three or four nights from 19 December 2000 to 18 January 2001. During each census we recorded air temperature, water temperature (only after 21 November), width and depth of the pond (PW and PD), and the calling intensity of each species of frog. Because of the difficulty of accessing the exact positions of calling frogs, we estimated breeding activity of each species based on their calling activity, a method that is often used for surveys of the 
breeding activity and abundance of frogs (e.g., Pierce and Gutzwiller, 2004; Steelman and Dorcas, 2010). Some calling individuals had been collected to confirm their identification during a preliminary survey in the previous year (1999) or were collected at the beginning of calling activity of each species in the present survey. We began each census between 20:00 and 21:00 and spent 30-60 min for each census, depending on the size of the pond and the abundance of frogs. Precipitation during the previous $24 \mathrm{~h}$ was measured and recorded every day at approximately 20:00. Water temperature was measured at $5 \mathrm{~cm}$ depth near (ca. $1 \mathrm{~m}$ from) the edge of the pond. The PW was measured approximately from the deepest point of the pond straight to the western edge of the pond. The PD was measured near the deepest point. Calling intensity was evaluated and categorized into the following six levels.

Level 0: no vocalizations were heard during the census.

Level 1: single or a few calls were heard during the census, but did not constitute a chorus.

Level 2: calls or choruses were heard intermittently, but for most of the time no vocalizations occurred.

Level 3: calls or choruses were frequently heard, but silent intervals were still obvious.

Level 4: intensive choruses were heard during most of the census, but occasional cessation of the chorus was detected.

Level 5: choruses were intensive and never ceased during the census.

After evaluating the call intensity some frogs were captured by hand and were brought to the field station, where they were identified and/or measured (snout-vent length and body mass). Sex was determined by either the presence of vocal sacs or enlarged arms in males or the presence of eggs in females. Frogs were marked by clipping the tip of the fourth finger so as not to measure the same individuals multiple times. The clipped toes were preserved in $99 \%$ ethanol for future DNA analyses. Frogs were released at the site of capture the next morning, except for a few individuals that were fixed with formalin and preserved in ethanol as reference specimens.

In the second season (2003-2004), we made censuses in a similar manner as in the first season but less frequently (generally every two to three days until mid-April and thereafter approximately once a week). No environmental measurements were recorded because the major objective of that season was to confirm the reproductive period of frogs. The data on precipitation were obtained from Projet ANGONOKA by the Durrell Wildlife Conservation Trust, but only for the period between October and December 2003. We generally started each census between 20:00 and 21:00. Calling intensity was evaluated and categorized in the same manner as during the first season, except that levels 2 and 3 were combined because of the occasional ambiguity in the discrimination of these two categories.

During our long-term field research on the terrestrial vertebrate community in the Ampijoroa forest, which extended from 1999 to 2014 , we surveyed the anuran fauna in this forest and confirmed the species that breed in the above temporary pond almost every rainy season. When we found species that had not been collected in the temporary pond during the intensive study, we collected them for identification and measurement. We especially noted any frog calls that were not heard in the temporary pond, to confirm the breeding sites for those species.

\section{RESUlts}

Throughout the long-term research period, a total of 12 species of frogs was collected, including one seemingly undescribed species of Stumpffia (Table 1). Among them eight species were confirmed to breed in the temporary pond (see below), of which calls were mostly heard at night. Breeding calls of two of the remaining four species were confirmed either in a small stream near Lake Ravelobe (Mantidactylus ulcerosus) or on the forest floor around the campsite, where males call 
TABLE 1. Anuran species observed in the Ampijoroa forest. Numerals in parentheses are sample size and range.

\begin{tabular}{|c|c|c|c|c|c|}
\hline Family & Species & $\begin{array}{l}\text { Breeding at the } \\
\text { temporary pond }\end{array}$ & Sex & $\begin{array}{l}\text { Snout-vent length } \\
(\mathrm{mm})\end{array}$ & Body mass (g) \\
\hline \multirow[t]{3}{*}{ Hyperoliidae } & Heterixalus luteostriatus & Confirmed & Male & $30.4(23,27.0-32.8)$ & $1.3(23,0.9-1.8)$ \\
\hline & Heterixalus tricolor & Confirmed & Male & $29.1(6,28.0-30.6)$ & $1.6(5,1.3-2.0)$ \\
\hline & & & Unkown & $32.3(1)$ & $2.6(1)$ \\
\hline \multirow[t]{8}{*}{ Mantellidae } & Blommersia wittei & Confirmed & Male & $23.6(6,22.2-25.5)$ & $1.1(6,0.9-1.2)$ \\
\hline & & & Female & $26.3(1)$ & $1.4(1)$ \\
\hline & Boophis doulioti & Confirmed & Male & $44.1(6,38.1-55.8)$ & $5.4(6,2.4-13.5)$ \\
\hline & & & Unkown & $40.6(12,18.6-53.0)$ & $4.4(12,0.6-10.1)$ \\
\hline & Laliostoma labrosum & Confirmed & Male & $56.6(68,49.3-67.5)$ & $11.3(67,6.3-22.3)$ \\
\hline & & & Female & $67.2(25,58.5-81.4)$ & $25.6(25,13.3-46.7)$ \\
\hline & Mantidactylus ulcerosus & Not confirmed ${ }^{a}$ & Unkown & $22.6(4,17.5-33.0)$ & $1.9(4,0.8-4.8)$ \\
\hline & Mantella ebenaui & Not confirmed ${ }^{b}$ & Unkown & $21.8(1)$ & $0.7(1)$ \\
\hline \multirow[t]{2}{*}{ Dicroglossidae } & Hoplobatrachus tigerinus & Confirmed & Male & $177.5(2,165-190)$ & $638(2,596-680)$ \\
\hline & & & Female & $200(1)$ & $925(1)$ \\
\hline \multirow[t]{2}{*}{ Ptychadenidae } & Ptychadena mascareniensis & Confirmed & Male & $33.0(43,28.2-37.4)$ & $2.4(43,1.5-3.4)$ \\
\hline & & & Female & $42.6(15,35.2-49.8)$ & $5.7(15,3.1-9.1)$ \\
\hline \multirow[t]{5}{*}{ Microhylidae } & Dyscophus insularis & Confirmed & Male & $42.5(1)$ & $16.1(1)$ \\
\hline & & & Female & $49.4(3,48.7-50.0)$ & $18.5(3,18.2-18.9)$ \\
\hline & & & Unkown & $54.4(4,43.0-55.9)$ & $12.2(4,8.1-16.1)$ \\
\hline & Scaphiophryne calcarata & Not confirmed ${ }^{b}$ & Male & $33.3(1)$ & $3.1(1)$ \\
\hline & Stumpffia sp. ${ }^{\mathrm{c}}$ & Not confirmed $^{d}$ & Male & $13.5(4,13.2-13.9)$ & $0.25(4,0.2-0.3)$ \\
\hline
\end{tabular}

${ }^{a}$ Breeding calls were confirmed in a small stream near Lake Ravelobe

${ }^{\mathrm{b}}$ Breeding calls were not confirmed in Ampijoroa

${ }^{\mathrm{c}}$ Possibly undescribed species

${ }^{\mathrm{d}}$ Calling males under leaf litter on forest floor around the campsite were confirmed

from under leaf litter (Stumpffia sp.). Several individuals of Scaphiophryne calcarata were collected in the forest as well as near the temporary pond, but their call was not confirmed. A single individual of Mantella, which was temporarily identified as M. ebenaui, was collected in the campsite, but its call was not heard and its breeding site was not determined.

In 2000, the first heavy rain occurred on 21 October. However, continuous rainfall did not start until 18 November, after which PW continued to increase (Fig. 1). Because of the inability of access to the deep water, maximum measurable PW and PD were $40 \mathrm{~m}$ and $50 \mathrm{~cm}$, respectively. Air temperature seemed to increase slightly during the first few weeks after initial rainfall and then remained relatively stable, with only minor fluctuations (Fig. 1). Water temperature showed a pattern similar to air temperature, but was usually 4 to 6 degrees higher than air temperature.

The eight species for which breeding calls were confirmed were one ptychadenid, Ptychadena mascareniensis, three mantellids, Laliostoma labrosum, Boophis doulioti, Blommersia wittei, one dicroglossid, Hoplobatrachus tigerinus, two hyperoliids, Heterixalus luteostriatus and $\mathrm{H}$. tricolor, and one microhylid, Dyscophus insularis. Ptychadena mascareniensis and L. labrosum are small- to medium-sized frogs and were observed in either in shallow water or on grassy ground. Hoplobatrachus tigerinus, a large species in which SVL reaches $200 \mathrm{~mm}$, was always found in water. Dyscophus insularis was usually found in shallow water, under vegetation around the pond. The remaining four species are relatively small frogs and were usually found on vegetation above or around water at a height of up to 2-3 m. 


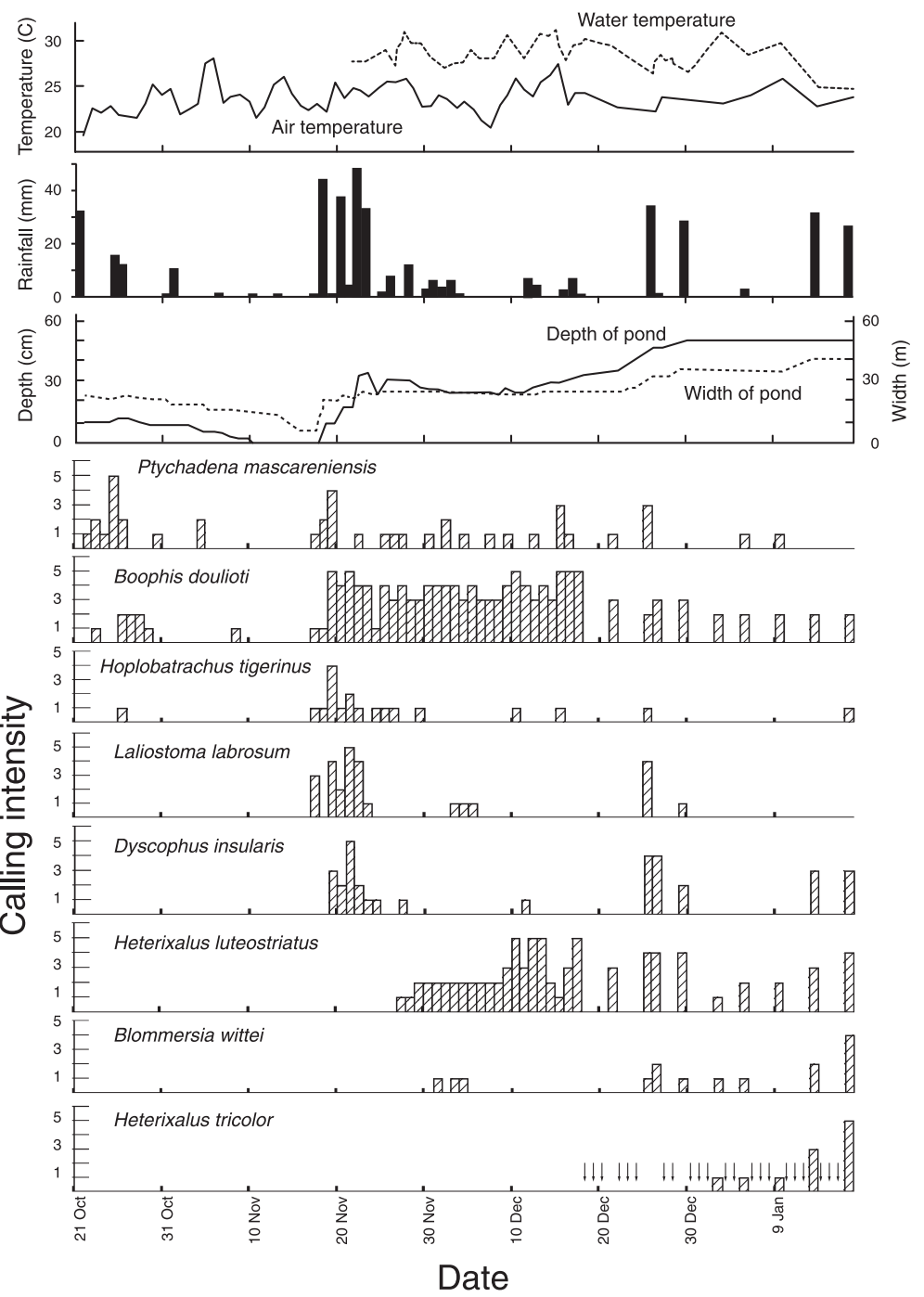

FIG. 1. Temporal changes in air and water temperatures, rainfall, depth and width of the pond, and calling level of eight species of frogs recorded in a temporary pond in Ampijoroa at night from 21 October 2000 to 18 January 2001. Arrows indicate the dates when a census was not made. Precipitation was measured every $24 \mathrm{~h}$. See text for the definitions of calling level and for the method of measurement of pond width and depth.

Heavy rainfall seems to affect the initiation of calling activity in several species of frogs. Ptychadena mascareniensis and Boophis doulioti were heard calling soon after the first heavy rain on 21 October 2000 (Fig. 1). Intensive calling activity of Hoplobatrachus tigerinus, $L$. labrosum, and $D$. insularis were heard after the second heavy rain, around 20 November 2000. A similar tendency was observed in the second season for B. doulioti,
H. tigerinus, and L. labrosum (Fig. 2). On the other hand, calling activity in two species of Heterixalus and Blommersia wittei seemed to start in late November to early January, when the pond accumulated sufficient depth and width of water (Figs. 1 and 2). Calling activity of Hoplobatrachus tigerinus, L. labrosum, and $D$. insularis usually occurred in a bout of two to six days, which seems to correspond to heavy rainfall (Figs. 1 and 2). 


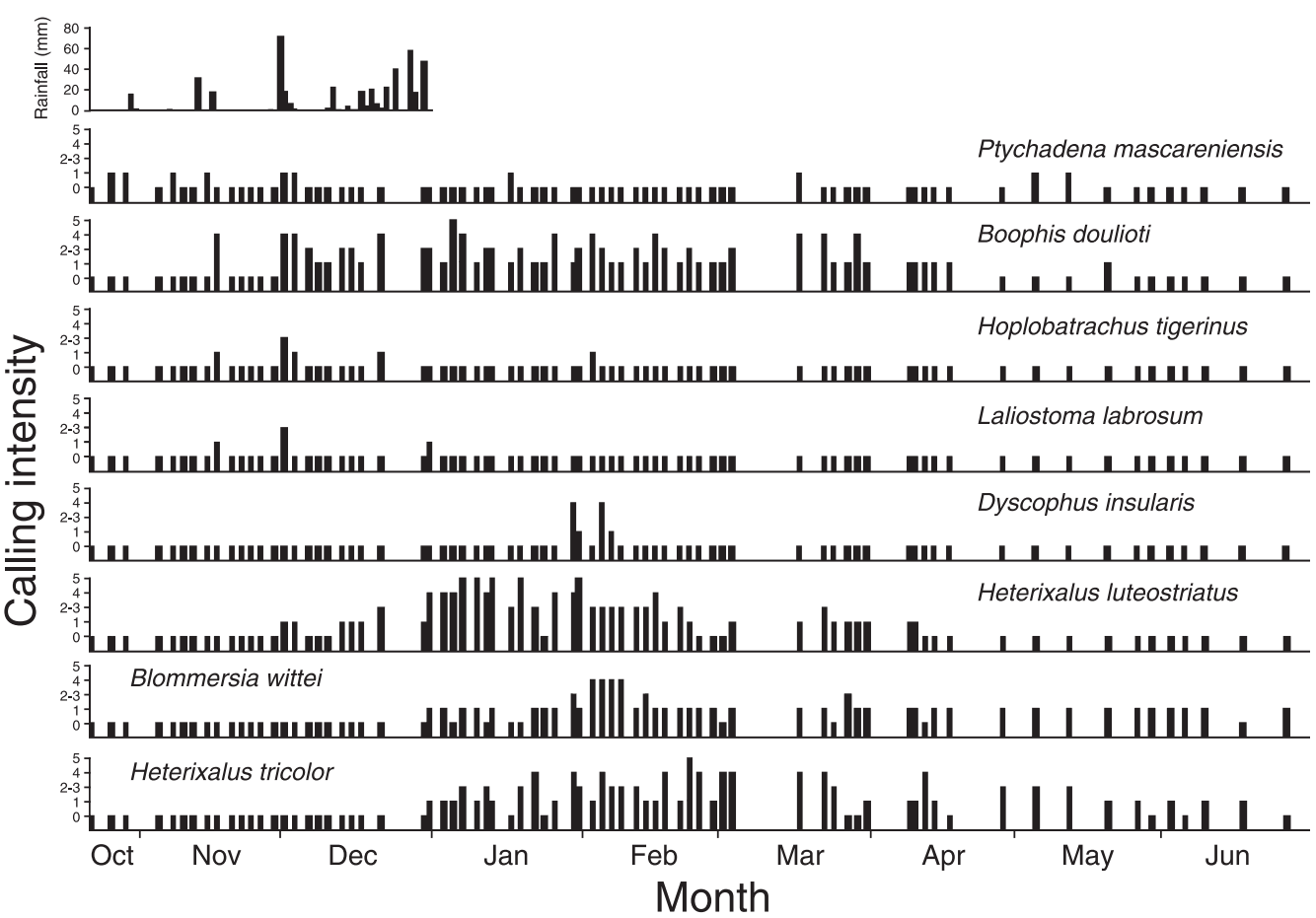

FIG. 2. Temporal changes of calling level of eight species of frogs recorded in a temporary pond in Ampijoroa at night from 22 October 2003 to 26 June 2004. See text for the definitions of calling level. Note that calling intensity 0 (lowest columns) indicates no calling activity and that days without columns indicate the dates when a census was not made. Precipitation data were provided from Projet ANGONOKA by Durrell Wildlife Conservation Trust.

Boophis doulioti, two species of Heterixalus, and Blommersia wittei showed a prolonged calling period, which lasts four to six months (Fig. 2). Calls of H. tricolor and B. wittei were heard even in the early dry season (May and June), when no rainfall usually is recorded. The calling period of $M$. mascareniensis also seems long, but its pattern is not clear, and calling activity seems most intense during the first one-third of the rainy season (Figs. 1 and 2). Although we did not conduct a systematic census throughout the dry season, we rarely heard, during the long-term research period, frog calls in the temporary pond in the dry season, when little or no water remained.

\section{DISCUSSION}

Mori et al. (2006) reported nine species of frogs from Ampijoroa, based on the surveys conducted in two rainy seasons. We found three additional species of frogs (Mantidactylus ulcerosus, Mantella ebenaui, and Stumpffia sp.) during the long-term survey extended to 2014. Accordingly, two-thirds of the anuran species that inhabit the Ampijoroa forest were confirmed to breed in the temporary pond studied here. Mantidactylus ulcerosus and Stumpffia sp. obviously do not use the temporary pond as breeding sites: the former breeds along a small stream located ca. $1 \mathrm{~km}$ from the pond, and the latter breeds in the leaf litter of the forest floor. We did not confirm any calls or breeding sites of Mantella ebenaui and Scaphiophryne calcarata, although these frogs are reported to breed in stagnant pools or ponds (Glos, 2003; Glaw and Vences, 2007). During our long-term research from 1999 to 2014, we intermittently surveyed the tempo- 
rary pond throughout the rainy season and even during the dry season, but we never heard unidentified frog calls there. Thus, it is unlikely that these two species breed in the temporary pond we studied.

Frogs are generally categorized into two types based on the length of their breeding period: explosive breeders, in which breeding periods last from several hours to a few days; and prolonged breeders, in which breeding activity lasts up to several months (Stebbins and Cohen, 1995). Abrunhosa et al. (2006) defined a third category of temporal reproductive pattern for frog species in the rainforest of Brazil: opportunistic breeders, which have a short breeding period related to a specific environmental factor, especially rain. In the present study four of the eight species that breed in the temporary pond are categorized as prolonged breeders-Boophis doulioti, $H$. luteostriatus, H. tricolor, and Blommersia wittei-although the beginning of calling activity was different among them. The reproductive pattern of $P$. mascareniensis is unclear because less calling activity was observed, particularly in the second study season, but it seems more like a prolonged breeder. Laliostoma labrosum is categorized as a typical explosive breeder, in which breeding activity obviously corresponded to heavy rain in the earlier rainy season. We found nearly 100 individuals during a single night on the wet, grassy ground along the edge of the pond (Mori et al., 2006). In the second season, however, we did not record high calling intensity of this species. This could be due to the infrequent survey schedule, which may simply have missed the days of explosive breeding. The remaining two species, Hoplobatrachus tigerinus and $D$. insularis, seem also to be categorized as explosive breeders, in which calling activity corresponds to rainfall. These categorizations coincide with those of breeding activities observed in a Kirindy dry forest, where six of the eight species (i.e., excluding $B$. witte $i$ and H. tigerinus) are distributed (Glos, 2003).

Anuran communities often show temporal and spatial partitioning of reproductive activity, in particular in tropical regions with high species richness (e.g., Gottsberger and Gruber, 2004; Abrunhosa et al., 2006; Vasconcelos et al., 2011). As mentioned above, the breeding periods and patterns of the eight species in the temporary pond in Ampijoroa are different from each other to some extent. Nonetheless, calling activities often overlapped among most species: calls of all but $H$. tigerinus, which is an introduced species to Madagascar (Guibé, 1953; Vences et al., 2003), were heard on many of the same nights. Calling positions in relation to the temporary pond are also different among the species: two species of Heterixalus, Boophis doulioti, and Blommersia wittei usually call from leaves and tree branches, whereas the remaining four species call in water or on the ground around the pond (Mori et al., 2006). It is obvious that the temporary pond provides suitable breeding sites to the anuran community in the dry forest of Ampijoroa, with different types of microhabitats. To clarify the spatio-temporal partitioning and adaptive radiation of frogs in this forest, more detailed observations of reproductive activity are necessary for the eight species that use the temporary pond, as well as for the other four species that use other types of breeding habitat. Such studies are important to develop appropriate management policies for the conservation not only of Madagascan hyperdiverse amphibians (Andreone and Luiselli, 2003), but also of tropical dry forests, which constitute a seriously endangered ecosystem (Janzen, 1988; Lerdau et al., 1991).

\section{ACKNOWLEDGments}

We are grateful to $\mathrm{H}$. Takahashi and $\mathrm{B}$. Razafimahatratra for their invaluable assistance in collecting data during the second season. We thank T. Jono, R. Ito, Y. Kojima, and other members of our research team for their help in collecting animals and $\mathrm{F}$. Rakotondraparany, H. Rakotomanana and the staff of Madagascar National Parks, 
Ankarafantsika for their cooperation in conducting this research. This study was partially supported by Grants-in-Aid for International Scientific Research (B) (Field Research, nos. 11691183, 17405008, 21405007, and 24405008) from the Ministry of Education, Culture, Sports, Science, and Technology, Japan.

\section{Literature Cited}

Abrunhosa, P. A., Wogel, H., and Pombal, J. P. JR. 2006. Anuran temporal occupancy in a temporary pond from the Atlantic rain forest, south-eastern Brazil. Herpetological Journal 16: $115-122$.

Andreone, F. ANd Luiselli, L. M. 2003. Conservation priorities and potential threats influencing the hyper-diverse amphibians of Madagascar. Italian Journal of Zoology 70: 53-63.

Blaustein, L. and Schwartz, S. S. 2001. Why study ecology in temporary pools? Israel Journal of Zoology 47: 303-312.

EAson, G. W. JR. AND Fauth, J. E. 2001. Ecological correlates of anuran species richness in temporary pools: a field study in South Carolina, USA. Israel Journal of Zoology 47: 347-365.

Glaw, F. And Vences, M. 2003. Introduction to amphibians. p. 883-898. In: S. J. Goodman and J. P. Benstead (eds.), The Natural History of Madagascar. The University of Chicago Press, Chicago.

Glaw, F. And Vences, M. 2007. A Field Guide to the Amphibians and Reptiles of Madagascar, 3rd Edition. Vences and Glaw Verlags GbR, Köln.

Glos, J. 2003. The amphibian fauna of the Kirindy dry forest in western Madagascar. Salamandra 39: 75-90.

Goodman, S. M. And Benstead, J. P. 2005. Updated estimates of biotic diversity and endemism for Madagascar. Oryx 39: 73-77.

Gottsberger, B. AND Gruber, E. 2004. Temporal partitioning of reproductive activity in a neotropical anuran community. Journal of Tropical Ecology 20: 271-280.
GuiBÉ, J. 1953. Au sujet de l'introduction de Rana tigrina tigrina Daudin á Madagascar. Le Naturaliste Malgache 5: 241-242.

Ikeuchi, I., Hasegawa, M., AND Mori, A. 2012. Characteristics of sleeping sites and timing of departure from them in a Madagascan diurnal gecko, Lygodactylus tolampyae. Current Herpetology 31: 107-116.

JANZEN, D. H. 1988. Tropical dry forests: the most endangered major tropical ecosystem. p. 130 137. In: E. O. Wilson (ed.), Biodiversity. National Academy Press, Washington, D.C.

Lerdau, M., Whitbeck, J., ANd Holbrook, N. M. 1991. Tropical deciduous forest: death of a biome. Trends in Ecology and Evolution 6: 201-202.

Moreira, L. F. B., Machado, I. F., Lace, A. R. G. M., AND MaltchiK, L. 2007. Calling period and reproductive modes in an anuran community of a temporary pond in southern Brazil. South American Journal of Herpetology 2: 129-135.

Mori, A., Ikeuchi, I., ANd Hasegawa, M. 2006. Herpetofauna of Ampijoroa, Ankarafantsika Strict Nature Reserve, a dry forest in northwestern Madagascar. Herpetological Natural History 10: 31-60.

Pierce, B. A. And Gutzwiller, K. J. 2004. Auditory sampling of frogs: detection efficiency in relation to survey duration. Journal of Herpetology 38: 495-500.

Stebbins, R. C. And Cohen, N. W. 1995. A Natural History of Amphibians. Princeton University Press, Princeton.

Steelman, C. K. and Dorcas, M. E. 2010. Anuran calling survey optimization: developing and testing predictive models of anuran calling activity. Journal of Herpetology 44: 61-68.

Vasconselos, T. S., Dos Santos, T. G., RossaFeres, D. De C., And Hadado, C. F. B. 2011. Spatio-temporal distribution of calling male frogs in Morro Do Diabo State Park (southeastern Brazil): implications for conservation and management in a seasonally dry tropical forest. South American Journal of Herpetology 6: 107-118.

Vences, M., Raselimanana, A. P., and Glaw, F. 2003. Ranidae: Hoplobatrachus, Indian tiger 
frog. p. 926-927. In: S. J. Goodman and J. P. Benstead (eds.), The Natural History of Madagascar. The University of Chicago Press, Chicago.

Vieites, D. R., Wollenberg, K. C., Andreone, F., Köhler, J., Glaw, F., ANd Vences, M. 2009. Vast underestimation of Madagascar's biodiver- sity evidenced by an integrative amphibian inventory. Proceedings of the National Academy of Sciences of the United States of America. 106: 8267-8272.

Accepted: 24 June 2015 